\title{
O estudo dos fenômenos térmicos-ambientais através da metodologia em espiral
}

The study of thermal-environmental phenomena using spiral methodology

\author{
L. S. Leal ; F. C. L. Ferreira; L. M. Gomes \\ Faculdade de Física, Instituto de Ciências Exatas, Programa Nacional de Mestrado Profisional em Ensino de Física, \\ Universidade Federal do Sul e Sudeste do Pará, 68507-590, Marabá - Pará, Brasil \\ *lsl_icc@yahoo.com.br
}

(Recebido em 26 de fevereiro de 2019; aceito em 16 de maio de 2019)

\begin{abstract}
Este trabalho, utiliza a metodologia "ensino em espiral", com a finalidade de levar os alunos a compreender a relação dos fenômenos físicos, térmicos e naturais: inversão térmica, efeito estufa, ilhas de calor e aquecimento global, abordando os conceitos de umidade, radiação infravermelha e pressão atmosférica. Para isso, utilizou-se aulas práticas com experiências de materiais de baixo custo, mapa conceitual e o LEGO. Nas aulas, aplicou-se uma sequência didática metodológica cujo objetivo foi incentivar a reflexão sobre os conceitos ambientais trabalhados, além disso, os estudantes foram submetidos a uma análise qualitativa e quantitativa por meio de redação, com intuito de comprovar a eficiência da proposta didática. Os dados foram obtidos na escola estadual de ensino médio Lourenço Galleti na cidade de Açailândia - MA. Portanto, verificou-se que os resultados dos alunos avaliados forma significativos com relação aos conceitos abordados. Ainda aplicou-se o método estatístico (ANOVA), através do qual foi possível avaliar o nível de compreensão dos estudantes entre as turmas do terceiro ano $\mathrm{A}$ e $\mathrm{C}$ envolvidas na pesquisa. Com esse método observou-se a disparidade entre os níveis de aprendizagem das duas turmas, a turma $\mathrm{C}$ apresentou resultados melhores significativamente do que a turma A. Dessa forma, conclui-se que a proposta se torna eficaz, desde que haja uma análise dos conhecimentos prévios e dos possíveis obstáculos epistemológicos de cada turma afim de obterem o mesmo rendimento com a intervenção docente.

Palavras-chave: espiral, aquecimento global, sequência didática.
\end{abstract}

This work uses the "spiral teaching" methodology, in order to take students to understand the relation of physical, thermal and natural phenomena: thermal inversion, greenhouse effect, heat islands and global warming, addressing the concepts of humidity, infrared radiation and atmospheric pressure. For this, we used practical classes with experiences of low cost materials, conceptual map and LEGO. In the classes, a didactic methodological sequence was applied whose objective was to encourage reflection on the environmental concepts worked, in addition, the students were submitted to a qualitative and quantitative analysis through writing, in order to prove the effectiveness of the didactic proposal. Data were obtained from Lourenço Galleti State High School in the city of Açailândia - MA. Therefore, it was verified that the evaluated students' results were significant in relation to the concepts discussed. We also applied the statistical method (ANOVA), through which it was possible to evaluate the level of comprehension of the students between the third year classes $\mathrm{A}$ and $\mathrm{C}$ involved in the research. With this method the disparity between the levels of learning of the two groups was observed, the group $\mathrm{C}$ presented better results significantly than the group A. In this way, it was concluded that the proposal becomes effective, as long as there is an analysis of the knowledge and possible epistemological obstacles of each class in order to obtain the same income with the teacher intervention.

Keywords: spiral, global warming, didactic sequence.

\section{INTRODUÇÃO}

Nos últimos anos, observa-se um aumento considerável de gases poluentes lançados na atmosfera (dióxido de carbono, metano, óxido nitroso, clorofluorcarbonos, hidro clorofluorcarbonos, Ozônio, hexa fluoreto de enxofre, entre outros), provindos de fontes poluidoras, na maioria das vezes encontradas nas cidades: automóveis, indústrias, etc [1].

Para se ter uma ideia, antes da revolução industrial a concentração de dióxido de carbono se manteve estável na ordem de 280 partes por milhão (ppm) por milhares de anos. No entanto, com a invenção do motor de combustão em 1900, pertencente aos carros, essa taxa disparou, chegando a superar 400ppm em 2017 [2]. 
Além disso, a paisagem modificada dessas metrópoles agravam ainda mais os efeitos da sensação térmica nas pessoas que ali se encontram, pois materiais como o concreto e asfalto, frequentemente encontrados nas mesmas, esquentam rapidamente, emitindo uma grande quantidade de radiação térmica para o meio ambiente [3].

Aliado a isso, a construção de edifícios cada vez maiores, prejudica a circulação do vento, aprisionando ainda mais calor de forma localizada, prejudicando a qualidade de vidas das pessoas que moram nestas cidades, provocando fenômenos como: inversão térmica e ilhas de calor; cada vez mais comuns no dia a dia [3]. Esse aumento de temperatura, deixa de ser localizado, alcançando proporções globais, na medida em que o sistema térmico da terra é resultado da integração de todos as partes do planeta, ou seja, um influencia o outro [3], logo gera consequências graves no meio ambiente, como alterações nos ecossistemas, as quais levam à extinção de diversas espécies do nosso planeta [4].

Nesse sentido, devido ao crescimento destas problemáticas ambientais no planeta, o governo federal, sentiu necessidade de criar a Lei $\mathrm{n}^{\circ}$ 9.795/99, instituindo a política nacional que rege:

\footnotetext{
"Os processos por meio dos quais o indivíduo e a coletividade constroem valores sociais, conhecimentos, habilidades, atitudes e competências voltadas para a conservação do meio ambiente, bem de uso comum do povo, essencial à qualidade de vida e sua sustentabilidade" [5].
}

Esses conceitos ambientais (radiação, umidade e pressão atmosférica) foram trabalhados para explicarem os fenômenos térmicos naturais (ilhas de calor, inversão térmica, efeito estufa e aquecimento global) devendo ser aproveitados de forma articulada em todos os níveis e modalidades do processo educativo (fundamental, médio e superior), seja caráter formal e nãoformal (art. 2). Sendo que dentre os princípios básicos deste projeto, devem constar (art. 4, II e VII):

\begin{abstract}
"II - a concepção do meio ambiente em sua totalidade, considerando a interdependência entre o meio natural, o socioeconômico e o cultural, sob o enfoque da sustentabilidade; VII - a abordagem articulada das questões ambientais locais, regionais, nacionais e globais" [5]
\end{abstract}

Logo, a partir deste momento, o professor vai ter que se adaptar à nova realidade desta lei, criando metodologias diferenciadas na forma de ensinar o conteúdo obrigatório de Física. Neste trabalho, foi criada uma sequência didática, com o intuito de provocar no aluno, uma mudança de atitudes, na medida em que aprende novos conhecimentos [6], como por exemplo, fazer que os estudantes saibam da importância de preservar as árvores, pois as mesmas são seres vivos que ajudam a deixar o ambiente mais úmido, ventilado e agradável.

\title{
2. MATERIAL E METÓDOS
}

O objetivo do ensino em espiral é desenvolver no aluno a vontade de procurar soluções para problemáticas que por ventura apareçam, para que posteriormente o mesmo seja capaz de elaborar questionamentos e construir novos significados em sua memória [7]. Idealmente, o papel do professor deve ser de o facilitador desse processo, contribuindo para que os estudantes desenvolvam hipóteses de solução desses questionamentos, criando um ambiente propício que desperte o interesse para descoberta de alternativas, tendo cuidado de elaborar questionamentos, que provoquem a vontade de explorar o meio e encontrar a resposta correta [7].

Para Bruner (2000) [7], antes de mais nada, o professor deve ter domínio sobre o conteúdo que vai ser ministrado aos seus alunos, saber também o nível de conhecimento prévio dos mesmos e organizar sua sequência didática de modo que não possa trazer problemas ao entendimento de seus estudantes. Procurou-se explicar primeiramente os conceitos mais gerais (radiação, umidade e pressão) para posteriormente relacioná-los com os mais específicos (fenômenos térmicos ambientais), de uma forma ativa, através do manuseio das experiências pelos alunos, sempre dirigida ou acompanhada pelo professor, e com isso o aluno não desanima ou desiste de realizar sua atividade conforme o ensino em espiral [7]. 
Neste sentido, a fim de saber o quanto esta sequência de atividade é eficiente, foram realizadas de forma experimental na escola "E.M. Lourenço Antônio Galletti", localizada no município de Açailândia-MA, para duas turmas do terceiro ano (A e C) as seguintes etapas:

- Introdução: Apresentação das experiências elaboradas pelo professor aos alunos e dividindo a sala em grupos de 4 a 5 alunos.

- Diálogo e comparação: O professor reserva um dia da semana para levar um grupo de cada vez ao laboratório.

- Conclusão: O professor explica o conceito ambiental ou fenômeno físico por trás das experiências.

- Generalizações: Apresentações dos resultados e síntese dos conceitos pelos alunos. Exposição e explicação das relações dos conceitos e fenômenos do mapa conceitual pelo professor.

- Prova ou exame: Os alunos fazem uma redação, a fim de avaliação com o tema ligado aos conceitos ambientais aprendidos.

- Avaliação e divulgação dos resultados: O professor analisa as redações, corrigindo os possíveis erros conceituais ou epistemológicos que por ventura possa surgir.

A Figura 1 mostra que as experiências procuraram elaborar conceitos ambientais de radiação eletromagnética (DVD), umidade (psicrômetro caseiro) e pressão atmosférica (balão).

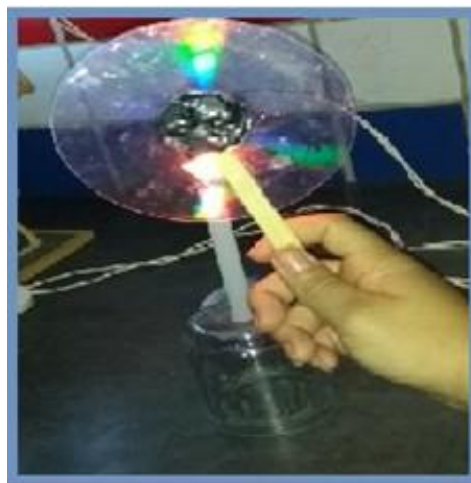

(a)

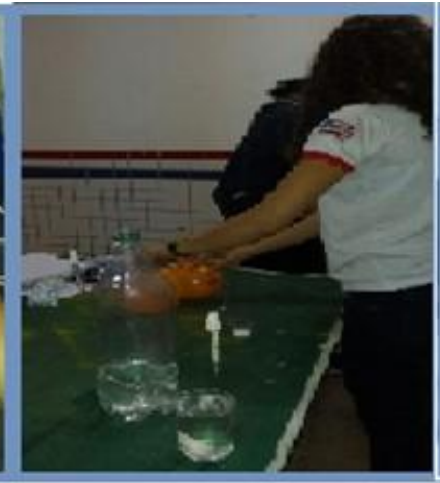

(b)

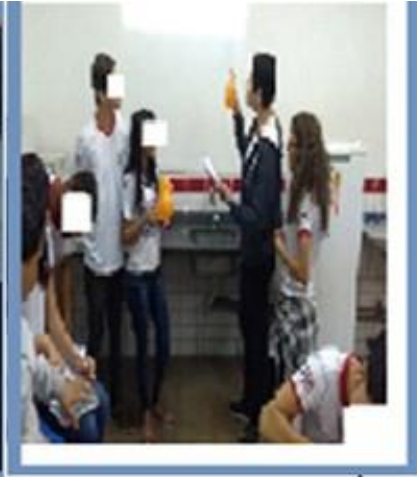

(c)

Figura 1: (a) Experiência do DVD; (b) Experiência do Psicrômetro; (c) Experiência do balão. Fonte: os autores.

A Figura 2 mostra os alunos realizando a experiência da caixa, a qual tem relação com o efeito estufa, além termo hidrômetro e do telhado, na qual abordam os conceitos de ilhas de calor, umidade, temperatura, dentre outros.

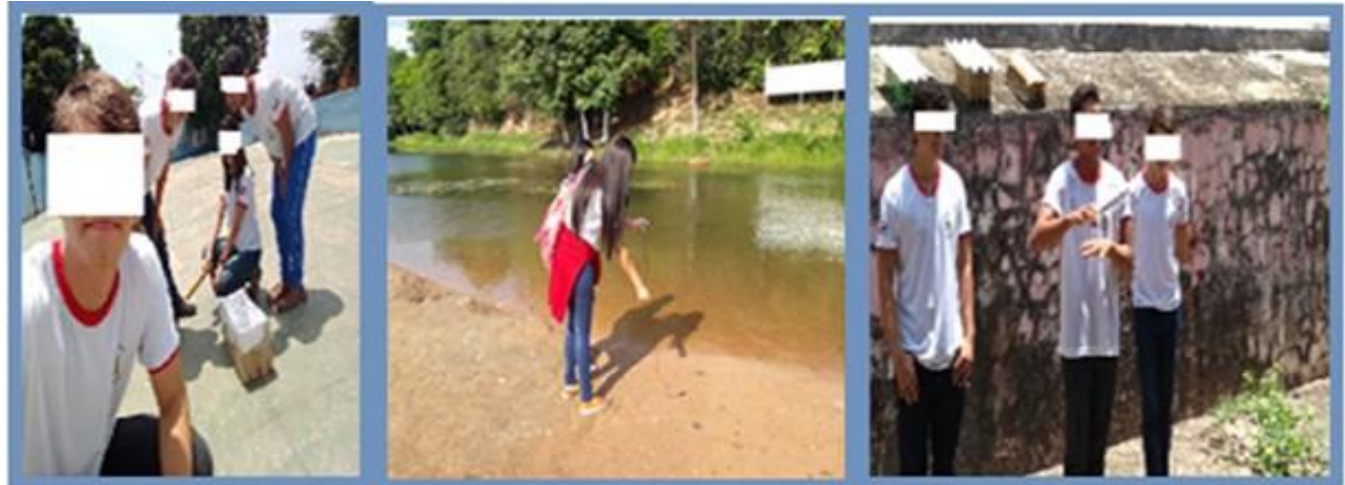

(a) (b) (c)

Figura 2-(a) Experiência da caixa; (b) Experiência do termo hidrômetro; (c) Experiência do Telhado. Fonte: os autores. 
Conforme relatado anteriormente, nessas experiências, o professor responsável procurou criar um ambiente propício para aprendizagem, elaborando um banco de questões que buscam estimular o aluno a descobrir respostas a estes questionamentos, através de hipóteses elaboradas para esta finalidade [7]. O objetivo final desta atividade é que o aluno seja capaz de entender os fenômenos físicos analisados, construindo novos significados, aplicados em sua realidade do dia a dia [8].

Estes questionamentos procuraram promover revisões periódicas de conceitos e atividades já aprendidas, discutindo novas relações deste conceito, através do chamado "ensino em espiral", na qual se trata de um entrelaçamento entre as perguntas que procura expandir a ideia completa dos conceitos aos poucos, a medida que o aluno vê e discute todas as experiências, onde mesmo chegará num entendimento completo sobre todos os conceitos e fenômenos térmicos ambientais [6].

Entretanto, somente após a fase da generalização, o estudante vai ter capacidade de entender todas as relações dos conceituais básicos ambientais (radiação infravermelha, umidade e pressão atmosférica) com os fenômenos térmicos ambientais (inversão térmica, ilhas de calor, efeito estufa e aquecimento global) analisados, pois nesta fase, o aluno entrará em contato com o mapa conceitual elaborado pelo professor, conforme a Figura 3 que mostrará visualmente a organização destes conceitos.

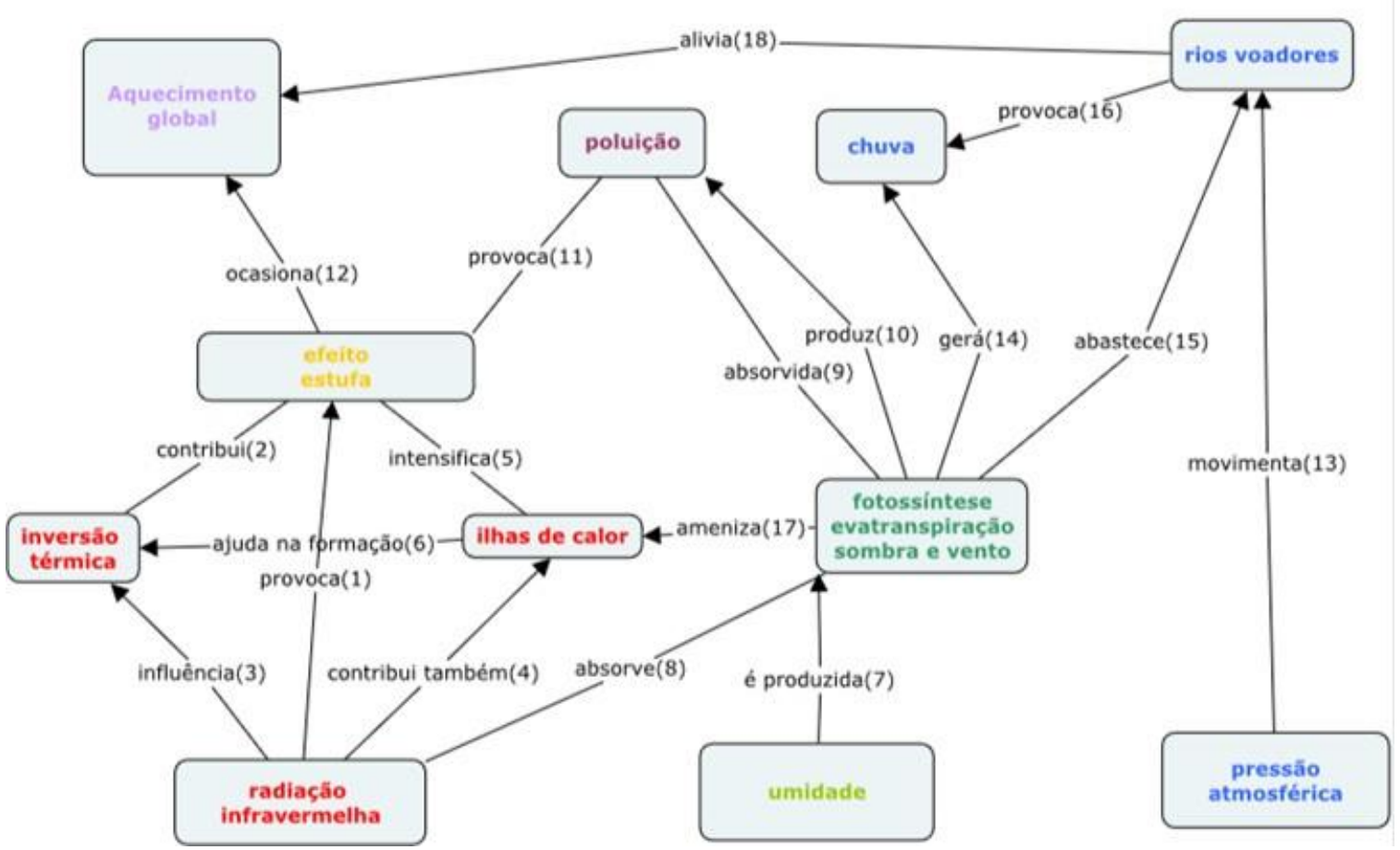

Figura 3: Mapa conceitual criado pelo professor. Fonte: imagem produzida no software Cmap Tools.

Este mapa conceitual sugere uma discussão, a lembrança pelos alunos dos conceitos ou ideias que aparecem ligados entre si, caso contrário perde sua funcionalidade [6]. Logo foi colocado no mapa palavras reduzidas (verbos ou locuções verbais), afirmações curtas que provocam a reflexão dos alunos. Neste sentido, apresentamos abaixo as explicações das afirmações, enumeradas, ligando os conceitos nos diagramas:

1) O aprisionamento da radiação infravermelha na terra provoca o fenômeno do efeito estufa.

2) Atualmente, a intensificação deste fenômeno contribui para ao aparecimento cada vez mais frequente da inversão térmica nas cidades.

3) Isto tem a ver com a radiação infravermelha que influencia na formação tanto do efeito estufa, quanto da inversão térmica.

4) O excesso de radiação infravermelha apricionada nas cidades contribui também para a formação de ilhas de calor.

5) Logo o efeito estufa intensifica a sensação de calor nas cidades. 
6) Neste sentido, tanto o fenômeno da inversão térmica quanto das ilhas de calor ajudam na formação de um e outro, ja que são ligados as mesmas causas.

7) Uma alternativa seria o aumento das áreas verdes nas cidades, pois as umidade no ar aumentaria, produzida pelo processo de evapotranspiração das plantas em geral.

8) Esta umidade que também é produzida pela fotossíntese, absorve o calor do ambiente.

9) Além da poluição que também é absorvida pelo processo da fotossíntese.

10) Mesmo que durante a noite também produz um pouco de poluição através inverso da fotossíntese, chamada de respiração, mas no balanço geral, está poluição é insignificante.

11) Nos últimos anos efeito estufa estar sendo intensificado provocado pelo excesso de poluição lançado no meio ambiente.

12) Logo, gerando consequência graves para o planeta como aparecimento do aquecimento global, ocasionado pelo aumento do mesmo.

13) A diferença de pressão atmosférica entre as regiões do Brasil influencia na movimentação dos rios voadores entre as regiões brasileiras.

14) Isto acontece devido a umidade produzida pelas arvores da Amazônia, vindas do oceano em direção a floresta, funcionando como uma verdadeira bomba biótica que gera uma enorme quantidade de chuva neste ambiente.

15) Esta umidade é carregada através do vento alísios vindos da Amazônia em direção a outras regiões Brasileiras, abastecendo os rios voadores.

16) Esses rios voadores vindo da Amazônia carregados de vapor de água vão em direção sudeste, provocando chuva.

17) Portanto, os rios voadores, produzida pela evapotranspiração das plantas, ameniza os efeitos do calor.

18) Onde de forma integrada com outros ecossistemas, ajuda alivia os efeitos provocados pelo aquecimento global.

Para avaliar se a metodologia deste trabalho foi eficiente em termos de aprendizagem foi usado diversos teóricos, dente eles o pesquisador Ausbel que usa a teoria aprendizagem significativa como melhor forma de ensinar conhecimentos científicos aos estudantes de forma geral [9]. Esta Teoria diz que os conceitos mais específicos são amparados por outros conceitos mais gerais ou relevantes, chamados de "subsunçores", desenvolvidos através de experiências presenciadas durante seu dia a dia.

Outra teoria utilizada neste trabalho foi a TCC (Teoria da carga cognitiva) que procura ensinar o conhecimento, baseado na limitação da memória humana [9], na qual nos últimos anos ganhou popularidade no meio acadêmico, graças as descobertas do pesquisador Baddeley, notando pela primeira vez em uma de suas experiências a limitada na capacidade da memória de trabalho em processar as informações recebidas do meio (de 2 a 9 informações ao mesmo tempo), isto ocorre, devido as informações serem processadas de maneira consciente no cérebro humano, exigindo muito esforço da memória de trabalho conseguir levar esta informação para a memória de longo prazo, onde ocorre a aprendizagem [10].

Esta descoberta, fez o pesquisador Sweller a começar a notar a dificuldade de ensinar o ser humano sem considerar estas limitações da memória de trabalho, podendo gerar uma "carga de conhecimento" excessiva, provocando uma sobrecarregar desta memória que prejudica a aprendizagem deste aluno, sendo denominado pela primeira vez pelo mesmo de teoria da "carga cognitiva" [9].

Todavia não é somente esta limitação que o cérebro humano possui ao receber uma informação nova, mas também na questão do tempo que está informação fica armazenada na memória de trabalho, pois ao demorar reforçar está mensagem dita anteriormente pelo professor ao aluno (cerca de 20 minutos), a mesma é descartada pela está memória, dita também como de curto prazo, ocasionando o esquecimento desta informação [9]. No entanto, caso a atenção do aluno esteja dividida por outras fontes de informações presentes no seu meio que não seja a fala do professor, está mensagem dita pelo docente, se perde mais rapidamente, cerca de 18 segundos, segundo a TCC [9].

Para piorar, não existe garantia que este conhecimento cientifico ao chegar na memória de longo prazo seja assimilada de forma fiel ao discurso dito pelo professor, pois neste estágio de subsunção, ocorre o processo de "assimilação obliteradora", tal que este conhecimento assimilado pelo aluno, 
após um breve tempo, retém apenas ideias, conceitos e proposições mais gerais e estáveis, ou seja, as pertencentes a ideias ancoras modificadas pelo professor [6].

Para se ter uma ideia, estas ideias do senso comum são tão difíceis de supera-los, sendo capazes de modificar até mesmo o conhecimento cientifico que foi para a memória de longo prazo, que foi capaz de dá origem a uma nova teoria pedagógica, chamada de "obstáculos epistemológicos", do pesquisador Bachelard, também aproveitada neste trabalho para o entendimento dos resultados analisados [11].

\section{RESULTADOS E DISCUSSÃO}

De acordo com Vygotsky a "palavra" é a ferramenta usada pelo ser humano para expressar o seu pensamento [12], este trabalho classificou essas palavras, expressas numa redação redigidas pelos alunos, em forma de palavras chaves ou ideias centrais, tentando captar os pensamentos dos alunos, sua visão de mundo. Esta redação teve o seguinte tema:

"-Faça uma redação, explicando como a poluição do ar pode prejudicar o meio ambiente e o ser humano, colocando em risco o futuro do nosso planeta. (30 linhas)".

Esta atividade, pertencendo ao processo de avaliação da sequência didática, foi realizada com duas turmas, uma do $3^{\circ}$ ano $\mathrm{A}$ ( 20 alunos) e outra do $3^{\circ}$ ano $\mathrm{C}$ ( 28 alunos) da escolar analisada, entre os meses de novembro e dezembro de 2018.

As palavras obtidas nas redações foram classificadas em três categorias: expressões nominais, consequências geradas pela agressão no meio ambientes e medidas de combate a agressão ao meio ambiente, tal que seus resultados foram expostos na Tabela 1.

Tabela 1: Palavras e expressões retiradas das redações dos alunos.

\begin{tabular}{|c|c|c|}
\hline Expressões Nominais & Consequências & Medidas de combates \\
\hline Poluição das indústrias & Afeta a saúde & Preservação das árvores \\
\hline Poluição de forma geral & Extinção de espécies & Conscientização \\
\hline Poluição por pó, enxofre & $\begin{array}{l}\text { Derretimento das } \\
\text { calotas polares }\end{array}$ & Acordos diplomáticos \\
\hline Poluição por carros & Inundações & Reflorestamento \\
\hline Poluição das siderúrgicas & Falta de chuva/seca & Leis rígidas/crime \\
\hline Desmatamento & Ilhas de calor & $\begin{array}{l}\text { Projeto de preservação/ parques } \\
\text { ecológicos }\end{array}$ \\
\hline Gado & Efeito estufa & \\
\hline Queimadas & Aquecimento global & \\
\hline \multirow[t]{3}{*}{ Capitalismo } & Inversão térmica & \\
\hline & Mudança do clima & \\
\hline & $\begin{array}{l}\text { Mudança no } \\
\text { ecossistema }\end{array}$ & \\
\hline
\end{tabular}

Os resultados mostraram que $85 \%$ por cento da primeira turma $\left(3^{\circ}\right.$ ano A) lembraram da palavra "poluição", de forma generalizada, ou seja, sem especificar qual é a fonte geradora da poluição. A maioria desses alunos (cerca de 55\%) especificaram que os gases poluentes eram carregados de pó, enxofre e outros materiais, dando a entender que vinham das siderúrgicas encontradas aos redores da cidade de Açailândia Má. Esses resultados foram compatíveis aos apresentados da outra turma (Turma C), na qual os seus alunos afirmaram em suas redações que as indústrias de forma geral são responsáveis pela poluição do ar encontradas em sua cidade $(67,85 \%)$, mais especificamente as indústrias siderúrgicas $(39,28 \%)$.

Outra palavra lembrada pelos alunos destas turmas (A) foi a palavra "desmatamento", expressando a preocupação por parte desses estudantes pela derrubada excessiva dessas arvores, pois as mesmas são responsáveis em realizar o fenômeno da fotossíntese, prejudicando com isto a captação da poluição que tanto prejudica o meio ambiente (57,14\% do A). A palavra "queimada" $(35,71 \%$ do $\mathrm{C})$ foi manifestada pelos alunos no sentido de que a mesma contribui ainda mais para a destruição da vegetação primária da região Amazônica. 
Dentre as consequências notadas pelos alunos da poluição do ar, as mais lembradas pelos alunos foram: problemas respiratórios, inundações, extinção de espécies (devido a alteração do ecossistema) além da alteração do clima (provocando a falta de chuva e seca). Foram também comentadas pelos alunos, os diversos fenômenos físicos estudados nas diversas experiências como o efeito estufa, inversão térmica, ilhas de calor (só o grupo C) e até o aquecimento global.

Já as medidas de combate à poluição do ar, a maioria dos alunos disseram que o caminho da solução passa pela conscientização das pessoas dos danos provocados aos ecossistemas do planeta, intensificando o fenômeno do efeito estufa, principal causa do aquecimento global (20\% o A e $57,14 \%, \mathrm{o}$ C). Em outras medidas ditas pelos estudantes, os mesmos demostraram que entenderam o valor das arvores nos ecossistemas do planeta, dizendo que alternativas de aliviar os efeitos provocados pelo poluição, seriam: a criação de projetos de reflorestamento e de parques ecológicos. Alguns ainda disseram que a melhor alternativa de solução para esta problema ambiental, seria o homem aprender a viver em harmonia com a natureza. No entanto, isto é uma tarefa difícil, sendo necessários criar leis mais rígidas, de proteção ambiental, incentivando acordos diplomáticos entre os governos internacionais.

Entretanto, quando se procura fazer uma análise mais profunda entre as diferenças dos resultados das turmas A e C, foi usado o método estatístico chamado de ANOVA (Analise de variância) que compara não só a variação dos resultados dentro de cada tratamento, mas também entre os mesmos[13]. Neste sentido, procurou-se com isso, obter a reposta do seguinte questionamento: "Existem diferenças nos resultados dos conceitos manifestados pelos alunos entre as turmas A e C, expressos nas suas redações?"'

Para analisar esta resposta, foi utilizado o teste de significância para comparação de variáveis, o "teste F" [13]. Este teste permiti fazer a decomposição da variância total em partes atribuídas a causas conhecidas e independentes, e as causas residuais, de origem desconhecida e de natureza aleatória, comparando essas duas variáveis, usando para isso os valores dos quadrados médios $(\mathrm{QM})$ das mesmas.

$\mathrm{O}$ teste $\mathrm{F}$ na análise de variância, utiliza-se sempre no denominador o $\mathrm{QM}$ do resíduo, comparando sempre com a variância causada pelos efeitos do fator que está sendo estudado (tratamentos, blocos, linhas, colunas, dentre outros), localizada no numerador da equação (1).

$$
F=\frac{Q M \text { tratamentos }}{Q M \operatorname{Res} i ́ d u o}=\frac{Q M T r a t}{Q M R e s}
$$

Portanto, após obter o fator $\mathrm{f}$, denominado de " $\mathrm{f}$ calculado", compara-se com o valor " $\mathrm{f}$ tabelado" deste teste. Se o F calculado $\geq \mathrm{F}$ tabelado ou $\mathrm{F}$ crítico, logo o teste é significativo ao nível de significância $\alpha$ considerado, portanto, confirmando as diferenças entre os grupos, caso contrário, se F calculado < F tabelado, esta diferença não é significativa.

Neste trabalho foi usado este método para comparar as quantidades de palavras iguais obtidas entre os dois grupos analisados(A e C), para saber se foram próximos ou diferentes seus resultados, por exemplo, em relação as palavras substantivadas o $\mathrm{F}$ calculado $(2,64)<\mathrm{F}$ tabelado $(4,49)$, mostrando que não houve diferenças significativas dos resultados desses dois grupos, isto fica evidente quando se observa o gráfico da figura 4, na qual entre um intervalo da pergunta (x), entre os valores de 0 a 1,50, a turma $\mathrm{A}$ houve um crescimento nas quantidades de palavras acertadas (y) em relação a outra turma (C), no entanto isto não se repetiu entre o intervalo de 3 a 3,75 que já teve efeito contrário(os resultados de $\mathrm{C}$ foi superior aos de $\mathrm{A}$ ), logo mantendo-se no geral um padrão parecido de resultados entre estas duas amostras, na qual refletiu numa evolução parecida de aprendizagem dessas duas salas. 

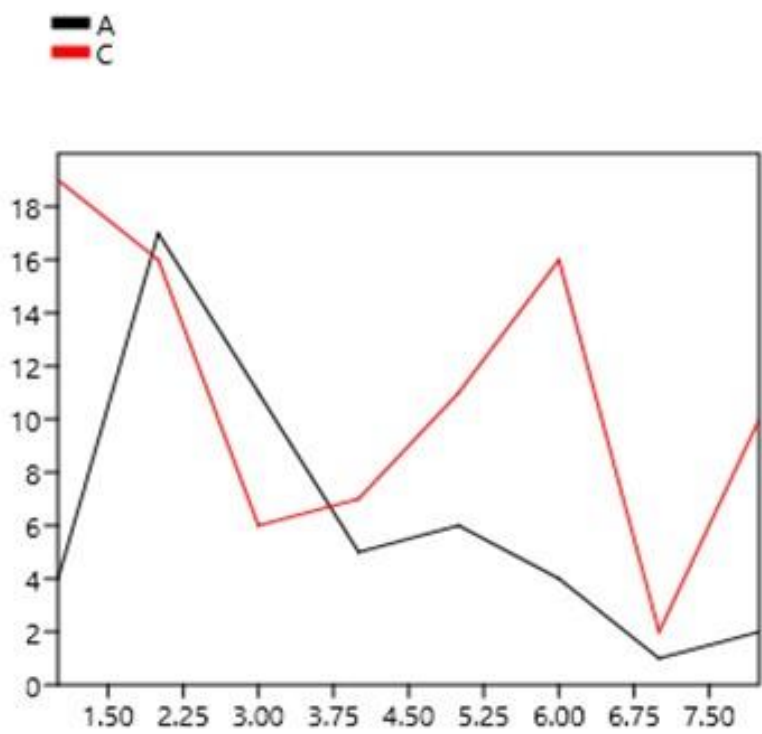

Figura 4: Gráfico de linha que representa as quantidades de expressões nominais ditas por grupo (y) $e$ intervalo entre uma pergunta e outra (x). Fonte: imagem produzida no software Past, versão 3.22,2018.

Entretanto, isto não se observa nos dados do fator "consequências" ditas pelos alunos, com um valor $f$ de " 4,82 ", acima do tabelado $(4,35)$, mostrando que existe diferenças significativas entre os grupos (A e C). Ao observar o gráfico da figura 5 de regressão linear, na qual é uma linha que melhor modela os dados, ou "linha de melhor ajuste", para a qual a soma dos quadrados dos resíduos é mínima, nota-se que os valores das turmas $\mathrm{A}$ e $\mathrm{C}$ se afastam um pouco desta reta de linear, confirmando as diferenças de resultados destes dois grupos.

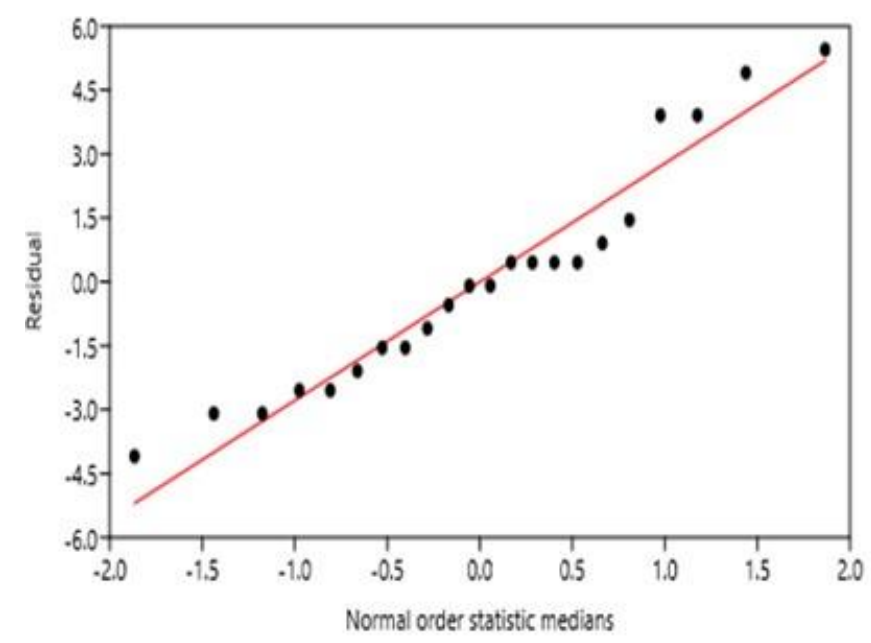

Figura 5: quantidades de acertos das consequências (y) pela variável independente da reta de regressão linear (x). Fonte: imagem produzida no software Past, versão 3.22,2018.

Em relação ao grupo de palavras pertencentes as "medidas para combater", apesar do teste f não indicar diferenças significativas entre as duas turmas (2,32 do f calculado, contra 4,96 do crítico), não se pode deixar de notar a grande diferença de quantidades de palavras ditas pelas turmas- 29 palavras da turma $\mathrm{C}$ contra $7 \mathrm{da} \mathrm{A}$. Isto é justificável, pois o teste $\mathrm{F}$ não leva em conta só as diferenças de resultados entre os grupos ao fazer seus cálculos, mas também os valores internos das amostras analisadas.

Analisando os resultados das redações dos alunos do terceiro ano da escola analisada, quando os mesmos expuseram a lista de consequências danosas que a poluição pode provocar ao meio ambiente, propondo medidas de combate, fica evidente que os mesmos conseguiram entender os fenômenos analisados, sendo capazes de elaborar, tais ideias derivadas, qualificadas ou 
superordenadas dos conceitos originalmente trabalhados, comprovando que a metodologia desenvolveu uma aprendizagem significativa nos estudantes [6].

Todavia, este efeito seria bem mais visível, se o fator "tempo", entre uma experiência, não fosse tanto extenso (média de 2 a 3 dias), já que a sequência didática obedeceu ao cronograma disponível da escola e da colaboração de outros professores para a realização das experiências, cedendo suas aulas, quando possível. Observou-se também nas redações uma disparidade das quantidades de palavras lembradas entre as turmas (A e C), sendo os resultados da turma do $3^{\circ}$ ANO C, bem superior ao A (em termos de consequência e medidas de combate). Isto mostra uma diferenças significante de esquemas ou conhecimento prévios [9] assimilados pelos alunos da turma A, em sua memória de longo prazo, comparados ao C, ocasionando diferenças na qualidade das redações entre as mesmas.

Já em relação aos tipos de conceitos ou palavras ditas nas redações pelos alunos, algumas fugiram um pouco dos conceitos interligados no mapa conceitual criado pelo professor, expondo palavras que se aproximam muito da realidade local deste alunado. Isto tem a ver com efeito da "assimilação obliteradora", na qual dizia o pesquisador Ausbel, pois o aluno acaba modelando o conhecimento cientifico aprendido na escola, numa forma mais estável, mais próxima do seu cotidiano, do seu senso comum, depois de passar um certo tempo [6].

Em relação aos obstáculos epistemológicos, alguns alunos confundiram o verbete "poluição", se confundindo com a poluição dos rios e das cidades, por lixos domésticos e esgotos:

"A poluição do ar causa diversas doenças respiratórias, principalmente em crianças e idosos, a poluição dos rios, ruas são responsáveis pelas enchentes avassaladoras" (Aluna do 3 C.).

Algumas vezes associando os gases poluentes ao estado sólido e não ao que seria o correto, o estado gasoso, logo podendo ser descartada ao meio ambiente, como se fosse uma lata de alumínio qualquer, muito próximo do chamado obstáculos substancialista de Bachelard (20 alunos):

“ (...) Os principais poluentes que são lançados nesses locais são o gás carbônico" (Aluna do $3 \mathrm{C}$ ).

“ (...) O risco do nosso planeta ficar sem oxigênio é muito alto" (Aluno do $3 \mathrm{~A}$ ).

Outro obstáculo que se percebe em alguns alunos é a confusão dos mesmos, em relação ao conhecimento dos gases que compõem atmosfera (oxigênio, nitrogênio, argônio, gás carbônico, etc.), achando que só se respira o gás oxigênio puro (4 no total). Esta maneira de pensar é provocada por experiências do dia a dia, pertencentes ao senso comum que possui um grande valor psicológico agregado no meio social em que ele vive, também chamado de experiência primeira:

“ Na formação do espírito científico, o primeiro obstáculo a ser superado é a experiência primeira" [10].

Por fim, uma aluna afirmou que as consequências geradas pela poluição do ar, pode levar a natureza reagir a agressão sofrida pelo homem, como se tivesse consciência ou vontade própria, se tratando, portanto, de um obstáculo animista.

\section{CONCLUSÃO}

A metodologia do ensino em espiral proposta por Bruner (2000) [7] apresentou ao longo do trabalho elementos suficientes que colaboraram com a diminuição da carga cognitiva intrínseca complexidade do conteúdo, dos estudantes.

Substancialmente, os resultados obtidos na análise das redações, mostraram a eficácia do método proposto nessa pesquisa, apesar das dificuldades de compreensão de alguns alunos a respeito da proposta metodológica e dos obstáculos apresentados ao longo do processo. Os instrumentos de apoio a realização da proposta, se apresentaram eficazes de um modo geral a eficácia da proposta, a exemplo, o material instrucional parte integrante dos experimentos cujo objetivo instigou nos estudantes o desejo de descobertas na resolução dos questionários propostos. 
Neste sentido, os alunos foram capazes de interpretar os conceitos aprendidos durantes as aulas experimentais, aproximando-os da realidade em que vivem. Dessa maneira os estudantes conseguiram ao longo atividades relacionar o conhecimento cientifico apresentado com os conhecimentos pré-existentes em sua memória de longo prazo, consequentemente, dando origem a um conhecimento mais estável proposto na teoria de Ausbel, uma espécie de subsunçor modificado.

A análise de variância mostrou que as turmas nem sempre apresentam resultados convergentes, obviamente, cada turma tem sua especificidade quanto a interpretação e compreensão dos conteúdos em função dos esquemas distintos entre cada membro da turma. Como visto, a duração das atividades foi prejudicial ao andamento do processo de modo eficaz, ou seja, pelo longo período entre as atividades os estudantes apresentaram problemas quanto a retomada dos conceitos. Além disso, seria importante diminuir as interferências externas, seja pela saída do aluno da sala de aula, excesso de conversa, entre outros, uma vez que as interrupções prejudicaram a lembrança das informações conceituais.

Outra sugestão seria a realização de exercícios, ajudando os alunos a fixarem o conteúdo ministrado pelo professor, podendo usar o recurso da técnica de exercícios resolvidos, ou até mesmo, estender os mapas conceituais entre uma experiência e outra, dando liberdade para que eles organizem suas ideias, hierarquizando de forma particular os conceitos assimilados, oportunizandoos explicarem os seus mapas conceituais ao público, seja de forma manuscrita ou de forma oral, possibilitando-os observarem as diferenças entre um conceito e outro, uma vez que na medida que interagem com os outros possibilitam o reconhecimento e a correção de erros conceituais durante as discussões, contribuindo em sua aprendizagem.

Em suma, acredita-se que esse trabalho possa contribuir com a melhoria da prática docente de um modo geral, não somente quanto ao ensino de Física mais em outras áreas do conhecimento por seu caráter interdisciplinar, além do fato de servir como suporte didático pedagógico nas atividades experimentais das escolas públicas do país.

\section{REFERÊNCIAS BIBLIOGRÁFICAS}

1. Montaigne F. Record $400 \mathrm{ppm} \mathrm{CO}_{2}$ milestone feels like we're moving into another era. 2.02. ed. Londres: Guardian, 2013.

2. Colapso do Ártico. Scientific American Brasil. 2018;183:18-19.

3. Kushnir Y. Solar Radiation and the Earth's Energy Balance. Palestra. In: Schlosser, Peter et al. The Climate System. Department of Earth and Environmental Science, Columbia University in the City of New York, 2000.

4. Primavesi O, Arzabe C, Pedreira MS. Aquecimento global e mudanças climáticas: uma visão integrada tropical. 1. ed. São Carlos: Embrapa Pecuária Sudeste, 2007.

5. BRASIL. Lei no 9.0705/1999. Política de Educação Ambiental. Brasília: MEC, 2000.

6. Moreira MA, Masini E. Aprendizagem significativa: a teoria de David Ausubel. 1. ed. São Paulo: Moraes, 1982.

7. Bruner J. A cultura da educação. 70. ed. São Paulo: Almedina Brasil, 2000.

8. Bordenave JD, Pereira AM. Estratégias de ensino-aprendizagem. 22a ed. Petrópolis: Vozes; 2001.

9. Sweller RJ. Instructional design consequences of an analogy between evolution by natural selection and human cognitive architecture. Instr Sci. 2004;32(1-2):1-8.

10. Baddeley AD. Your memory, a user's guide.1 ed., New York: Macmillan, 1982.

11. Bachelard G. A formação do espírito científico: contribuição para uma psicanálise do conhecimento. Rio de Janeiro: Contraponto, 1996.

12. Koll M. Vygotsky: Aprendizado e desenvolvimento: um processo sócio histórico. São Paulo: Scipione, 2006.

13. Toledo O. Estatística Básica. 1. ed. São Paulo: Atlas, 2010. 